\title{
AETIOLOGY AND RISK FACTORS FOR ORAL CANCER - A BRIEF OVERVIEW
}

S. K.S. Kumar, R. B. Zain. Aetiology and Risk factors for Oral Cancer - A Brief Overview. Annal Dent Univ Malaya 2004; 11: 41-50.

\begin{abstract}
Oral cancer is the sixth most common malignancy in the world. Despite recent advances in cancer diagnoses and therapies, the five-year survival rate of oral cancer patients has remained at a dismal $50 \%$ in the last few decades. Oral cancer is of major concern in Southeast Asia primarily because of the prevalent oral habits namely betel quid chewing, smoking and alcohol consumption. This paper provides a brief overview on the various aetiological agents and risk factors implicated in the development of oral cancer.
\end{abstract}

Key words: etiology, risk factors, oral cancer, oral precancer, carcinogenicity, tobacco, alcohol, nutrition, viruses, genetic predisposition.

\section{INTRODUCTION}

The three main factors which influence most diseases are lifestyle, environmental factors and genetic susceptibility (1). Oral or head and neck squamous cell carcinoma ( $\mathrm{SCCHN}$ ) development is influenced by all these factors namely tobacco (smoking \& smokeless), alcohol, diet and nutrition, viruses, radiation, ethnicity, familial and genetic predisposition, Candida infection, immunosuppression, the use of mouthwash, syphilis, dental factors, occupational risks and maté (2).

\section{LIFESTYLE FACTORS}

\section{Tobacco:}

Tobacco consumption continues to prevail as the most important cancer risk and tobacco accounts for millions of cancer deaths annually (3). The neoplastic diseases caused by smoking include cancers of the lung, oral cavity, pharynx, larynx, esophagus, urinary bladder, renal pelvis and pancreas (4). The oral consumption of smokeless tobacco in various forms also causes cancer, particularly in the oral cavity (5).

The relationship between smoking and oral cancer has been established firmly by epidemiological studies (6). The most important carcinogens in tobacco smoke are the aromatic hydrocarbon benz-pyrene and the tobacco specific
S.K.S. Kumar ${ }^{1}$ and R.B. Zain ${ }^{1}$

${ }^{1}$ Department of Oral Pathology,

Oral Medicine and Periodontology,

Faculty of Dentistry,

University of Malaya,

Kuala Lumpur 50603,

Malaysia.

Corresponding Author-Dr. Satish Kumar SK

nitrosamines (TSNs) namely 4-(nitrosomethylamino)1-(3-pyridyl)-1-butanone (NNK) and N'nitrosonornicotine (NNN). Animal studies have shown that NNK and NNN in the tobacco products causes tumours of the oral cavity, lung, esophagus and pancreas (7). NNK, NNN and their metabolites covalently bind with DNA of keratinocyte stem cells forming DNA adducts. These adducts are responsible for critical mutations involved in DNA replication (8). The metabolism of these carcinogens involves oxygenation by $\mathrm{P} 450$ enzymes in cytochromes and conjugation by glutathione-S-transferase (GST). Genetic polymorphisms in the genes coding for these enzymes are suspected to play a key role in the genetic predisposition to tobacco induced head and neck cancers (9). Certain other classes of enzymes are involved in the activation or degradation of carcinogens and procarcinogens and they are termed xenobiotic metabolizing enzymes (XMEs). These enzymes are found mainly in the liver and also in the upper aero-digestive tract mucosae. Many of the XMEs are polymorphic and they strongly influence the individual's biological responses to carcinogens by formation of DNA adducts. Hence, certain XME genotype may increase individual susceptibility to cancer through erroneous carcinogen metabolism leading to increased carcinogen exposure. The ability to repair damaged DNA by carcinogens, has also been found to be reduced in head and neck cancer patients (1).

Marijuana is a popular name for dried flowering leaves of the plant Cannabis Sativa and is also called bhang or ganja. It is smoked as cigarettes and the cannabinoids release potent carcinogens like benz(o)pyrene, phenols, phytosterols, acids and terpenes when burnt. Studies have shown that marijuana smoking is not an independent risk factor for oral cancer development. However, a theoretical risk exists because of composition of marijuana. Moreover, tobacco usually forms a part of marijuana smoking mix (10). 
The use of smokeless tobacco (tobacco consumed without combustion) has become prevalent all over the world (11). Smokeless tobacco is placed inside the oral cavity in contact with the mucous membranes where the nicotine is absorbed to provide the pharmacological effect (9). Smokeless tobacco has been used in many forms in different parts of the world. For instance, the use of oral snuff (wet or moist snuff) is more common in the west and the MiddleEast whereas betel quid chewing with a variety of forms and ingredients is widespread in Asia where it is a custom and cultural habit since ancient era. Consumption of smokeless tobacco causes mainly oral precancer and cancer (9).

In Western Europe and North America, the main types of chewing tobacco are plug, loose-leaf and twist. Their use is declining in these regions, albeit still prevailing in certain sub-populations (12). Moist snuff (ground tobacco) is particularly common in North America and Scandinavia. The habit has become extremely popular among youth in these countries especially Sweden $(12,13)$. The habit of oral snuff (referred to as snuff-dipping) causes a condition called 'snuff-dipper's cancer' which was the basis of classical description of verrucous carcinoma (9). Snuff as manufactured in Europe and North America is very different from snuff-like products used in the Middle East, which are made by smallscale industries. Swedish snus (snuff) is not fermented and contains very low nitrosamine levels compared to those produced elsewhere. To date there are still conflicting views on the carcinogenic potential of Swedish snuff $(9,14,15)$.

\section{Betel quid:}

Betel quid chewing with different ingredients is the most common habit in Southeast Asia especially in the Indian subcontinent. Betel quid (also referred to as pan or paan) usually contains betel-leaf (leaf of Piper betel vine), areca nut, slaked lime and tobacco. Other ingredients are often added namely, spices such as cardamom, cloves or aniseed are added in betel quid from India and turmeric in betel quid from Thailand (10). Some of the common forms of these mixtures are khaini (tobacco and lime), mishri (burned tobacco), zarda (boiled tobacco), gadakhu (tobacco and molasses) and mawa (tobacco, lime and areca) consumed in different parts of India; nass (tobacco, ash, cotton or sesame oil), naswarl niswar (tobacco, ash and lime) in Central Asia and Middle East; shammah (tobacco, ash and lime) in Saudi Arabia and toombak (tobacco and sodium bicarbonate) in Sudan (9). Studies have shown the association of these products with oral cancer development. For instance, shammah is associated with leukoplakia-like lesions and oral cancer (16).

Studies have shown the association of tobacco chewing with oral cancer (6) and precancer namely leukoplakia, erythroplakia and oral submucous fibrosis. (17-19).
Considerable research has been focused in the recent past on the carcinogenic, mutagenic and genotoxic potential of betel quid ingredients, especially tobacco and areca nut. In vitro studies on oral mucosal fibroblasts using DNA damage, cytotoxicity and cell proliferation assays have shown that some essential betel quid ingredients are genotoxic, cytotoxic and also stimulate cell proliferation (20). It has been shown that reactive oxygen species (ROS), methylating agents and reactive metabolic intermediates from betel quid induced various kinds of DNA damage (21). A recent IARC evaluation affirmed that chewing betel quid without tobacco is also carcinogenic to humans and areca nut, a common component of many chewing habits is carcinogenic to humans (22).

\section{Alcohol:}

Alcohol has been strongly implicated in the development of oral cancer. Based on the results of cohort and case-control studies, the consumption of alcoholic beverages has been considered carcinogenic to humans causing in particular, tumours of the oral cavity, pharynx, larynx, oesophagus and liver, although ethanol per se has not been proven carcinogenic in animal studies $(17,23$ 25).

Several epidemiologic studies $(17,23-26)$ done to determine the direct cause-effect relationship between alcohol consumption and development of oral cancer have found difficulty in establishing the same affirmatively due to other coexisting risk factors within the same individual such as smoking and quid chewing habits. However, alcohol consumption has been shown to act synergistically with tobacco in the increased risk of development of oral cancer $(17,23,24,26)$. Few studies (27-29) have managed to do analysis with patients who drink alcohol but are non-smokers and in patients who smoke but are non-drinkers. In one such study, alcohol has been found to be an independent risk factor for oral leukoplakia in an Indian population (27). However, similar studies evaluating the oral epithelial dysplasia occurrence in alcohol drinkers who are non-smokers, found that the role of alcohol in development of oral epithelial dysplasia is crucial only when considered in conjunction with tobacco $(28,29)$. Hence, the role of alcohol as an independent factor in oral carcinogenesis is still unclear albeit epidemiological evidence (23-26) establishes the synergistic role played by alcohol with tobacco.

The pathogenic mechanism of alcohol causing cancer has been difficult to establish. There have been many studies $(30,31)$ supporting possible mechanistic pathways of alcohol inducing carcinogenesis. Ethanol is shown to increase the permeability of oral mucosa producing an alteration in morphology characterized by epithelial atrophy which in turn leads to easier penetration of carcinogens into the 
oral mucosa. For instance, concentrations of ethanol of $25 \%$ and above significantly increased the permeability of porcine oral mucosa to nitrosonornicotine (NNN) (30). Substances that have been believed to be carcinogenic to humans have been seen in alcoholic beverages, a few examples being, $N$-nitroso compounds, mycotoxins, urethane, inorganic arsenic and others (25). The major metabolite of alcohol is acetaldehyde whose transformation is mainly carried out by the enzyme alcohol dehydrogenase (ADH). Acetaldehyde is then oxidized to acetate by means of aldehyde dehydrogenase (ALDH). Acetaldehyde causes DNA damage in cultured mammalian cells. It interferes with the DNA synthesis and repair. It also induces sister chromatid exchanges and specific gene mutations. Acetaldehyde inhibits the enzyme 06methylguanitransferase which is responsible for repairing injuries caused by alkylating agents. With all the above ill-effects of acetaldehyde which initiates or promotes tumour formation, increase in acetaldehyde accumulation in the body either due to increase in its production or due to decrease in its elimination, is considered deleterious (31). Accumulation of acetaldehyde can occur due to increased activity of alcohol dehydrogenase (ADH) enzyme activity which is present in oral microflora and in the oral mucosa. Poor oral hygiene with increasing microbial flora can increase $\mathrm{ADH}$ production thereby increasing acetaldehyde accumulation. ADH type- 3 genotypes cause rapid oxidation of alcohol to acetaldehyde and these individuals are predisposed to oral cancer. Alternately, reduction in aldehyde dehydrogenase (ALDH) enzyme can also lead to accumulation of acetaldehyde (31). Genetic polymorphisms have been reported in these two enzymes ADH and ALDH, which have been related to the increased risk of alcohol-related cancers. Cytochrome P450 IIE1 (CYP2E1), a xenometabolising enzyme (XME) present in smooth endoplasmic reticulum participates in the oxidation of ethanol and also in the metabolism of tobacco-associated $\mathrm{N}$-nitrosamines. Two genetic polymorphisms known in this enzyme predisposes to increased accumulation of acetaldehyde and indirectly by means of activating procarcinogens and increasing the production of radical toxins (31).

The systemic effects of alcohol are mainly due to the hepatic damage. Heavy alcohol consumption leading to cirrhosis and other diseases inhibits the detoxification of carcinogenic compounds such as $N$ nitrosodiethylamine (25). Chronic alcoholics tend to have reduced intake of nutrients due to the metabolic processes being occupied in the transformation of ethanol and the proper metabolism of nutrients is altered. This enhances nutritional deficiencies thereby increasing the risk of cancer. Chronic alcohol intake also leads to suppression of immune system by affecting liver, nutritional status and other body functions (25).

\section{Diet and Nutrition:}

The relationship between diet and nutrition to the risk of cancer development has been established by several epidemiological and laboratory studies (32-35). The earliest evidence was that of the iron deficiency caused Plummer-Vinson syndrome which led to the development of oral cancer in Swedish women. It was believed that patients with this syndrome also had deficiencies of vitamins $\mathrm{B}$ and $\mathrm{C}$ (36).

The working group of IARC has affirmed that low intake of fruits and vegetables predisposes to increased risk of cancer development (37). In Europe, diet has been accounted for $10-15 \%$ of oral cancer cases. More frequent consumption of fruit and vegetables, particularly of carrots, fresh tomatoes and green peppers were associated with reduced risk of oral and pharyngeal cancer (32). Food and food groups other than fruits and raw vegetables that have a protective effect are fish, vegetable oil, olive oil, bread, cereals, legumes, protein, fat, fresh meat, chicken, liver, shrimp, lobster and fiber $(33,34)$. Certain food groups have been shown to be associated with higher risk of oral cancer namely processed meats, cakes and desserts, butter, eggs, soups, red meat, salted meat, cheese, pulses, polenta, pasta or rice, millet and corn bread (34). The evidence from the above studies however does not allow authoritative attribution of either the benefit or the drawback to a specific ingredient in the food. This has contributed to the significant interest in studies focusing on the macronutrients (proteins, carbohydrates, fat, cholesterol) and micronutrients (vitamins and their analogues, trace elements) present in the food groups that are protective against cancer (38).

Considerable evidence has shown that certain micronutrients decrease the risk of oral cancer development and they include vitamins A (retinol), $\mathrm{C}$ (ascorbic acid) and $\mathrm{E}(\alpha$-tocopherol), carotenoids ( $\beta$-carotene), potassium and selenium (38-43). $\beta$ carotene, retinol, retinoids, vitamin $\mathrm{C}$ (ascorbic acid) and vitamin $\mathrm{E}$ ( $\alpha$-tocopherol) are antioxidants that are essential in reducing free radical reactions that can cause DNA mutations, changes in enzymatic activity, and lipid peroxidation of cellular membranes (44). However, some studies have also shown that $\beta$-carotene (45), vitamin $E$ (46) and vitamin $C$ (ascorbic acid) (47) may promote tumour development.

Carotenoids are a large group of yellow to red colored substances with various structural and biological characteristics that are present virtually everywhere in nature. Green leafy vegetables and many colored fruits are rich in carotenoids. Human serum contains $\beta$-carotene, alpha-carotene, 
cryptoxanthin, lycopene and lutein as major forms of carotenoids. $\beta$-carotene is the major form of provitamin $\mathrm{A}$, which are converted to vitamin $\mathrm{A}$ in the body. There are over 600 carotenoids in the human body of which only $10 \%$ are precursors of vitamin A. Although all the mechanisms involved in the anti-carcinogenic activity of carotenoids are not known, these agents serve as antioxidants, prooxidants, enhances the immune response, inhibits mutagenesis, reduces the induced nuclear damage (micronuclei), prevents sister chromatid exchanges, protects from various neoplastic events and protects against photo-induced tissue damage (48).

Retinol or the preformed vitamin $\mathrm{A}$ and its analogues are found in liver, egg yolks and other animal products $(40,48)$. Studies have shown that retinoids have the ability to suppress malignancy development in cultured cells and in animals, retinoid deficiency has led to increased risk of cancer development (38). Systemic or topical retinoid treatment has shown to cause regression of oral leukoplakia $(49,50)$. The major drawback of retinoid therapy are the side effects of hepatotoxicity and hypervitaminosis A (38).

$\beta$-carotene or the provitamin $\mathrm{A}$, is the most nutritionally active carotenoid and comprises 15 $30 \%$ of total serum carotenoids. Oxygen-dependent central cleavage of $\beta$-carotene and other carotenoids leads to formation of vitamin A. $\beta$-carotene and certain carotenoids quench highly reactive singlet oxygen and can block free-radical mediated reactions. In vitro studies have shown that $\beta$-carotene protects against sister chromatid exchange and other nuclear damage. A direct cause-effect relationship between $\beta$-carotene and risk of oral cancer has not been elucidated. This is not feasible as the cancer prevention activity of any substance could be proven only by large scale randomized, controlled clinical trial lasting for decades (39). Indirect evidence through short term case-control and cohort studies $(43,51,52)$ and laboratory studies (39) has clearly established the link between $\beta$-carotene and risk of oral cancer. However, $\beta$-carotene supplements has been shown to increase the incidence of lung cancers in smokers (45). Owing to the difficulty in conduction of large scale prevention trials, considerable interest was shown in the search for intermediate biomarkers which are usually measurable histologic, biochemical, genetic or other markers that occur during cancer development and which when displayed, places an individual at a higher risk. One such marker is the presence of micronucleated cells in the premalignant lesions and cancer which reflects the genotoxic damage produced by carcinogens (49). Several treatment trials with $\beta$-carotene have been done in oral precancer and cancer and have shown considerable success rates. Remission or regression of oral leukoplakia using $\beta$-carotene only or with vitamin A have been shown in many studies $(49,50$, 53). $\beta$-carotene is a non-toxic antioxidant to humans and is highly suitable for chemoprevention trials than retinoids such as 13-cis-retinoic acid which exhibit toxicity (39).

Alpha-tocopherol, the most active form of vitamin $\mathrm{E}$ is a powerful lipid-soluble antioxidant in cellular defense systems (54) and is found in green leafy vegetables, plant oils, margarine and wheat germ. Alpha-tocopherol protects cellular membranes from lipid peroxidation and enhances the mitogenic response, inhibit certain prostaglandins, and improves T-cell mediated responses (44). Vitamin E has been shown to prevent tumor formation in hamsters and this has been attributed to the stimulation of potent immune response by vitamin E (42) and vitamin E has also been shown to have the potential to reduce oxidative damage caused by hydroxyl radicals (54). Clinical intervention trials with alpha-tocopherol which is a non-toxic antioxidant like $\beta$-carotene have shown much promise with oral cancer and precancer. Regression of oral leukoplakia have occurred using vitamin $E$ (55). Alpha-tocopherol with $\beta$-carotene and/or ascorbic acid have shown to regress oral leukoplakia (56). However, treatment trials with alpha-tocopherol has to be done with caution as high concentrations $(80 \mu \mathrm{mol})$ of vitamin $\mathrm{E}$ has been shown to promote skin tumour formation (46).

Vitamin C (L-ascorbic acid/ L-AA) is found in citrus fruits, cruciferous vegetables and other fruits like mangoes, kiwi, strawberries, honeydew, papaya and cantaloupe. Ascorbic acid is an antioxidant, decreases nitrosation by preventing the formation of nitrosamines thereby acting as a chemo-preventive agent. It also affects the activity of leukocytes and macrophages. Ascorbic acid (AA) is also involved in the activity of cytochrome P-450 which is important in the inactivation of potent carcinogens and metabolic activation of procarcinogens $(38,44)$. Laboratory studies have shown that ascorbic acid inhibited tumour development (38). In contrast, Schwartz et al. (47) had shown that oral administration of L-ascorbic acid dissolved in heavy mineral oil enhances tumour development in the hamster buccal pouch experimental model. Serum vitamin $\mathrm{C}$ was decreased along with other antioxidants in leukoplakia patients as compared to controls (51). There has been no study reported on the sole use of ascorbic acid in the treatment of oral leukoplakia. However, Tuovinen et al. (1992) showed that the prevalence of leukoplakia was higher when smoking was combined with AA deficiency (41). The association between ascorbic acid and oral cancer is based on the dietary assessments that low intake of fruits and vegetables which are usually rich in vitamin $\mathrm{C}$ predisposed to increased risk of oral cancer (44).

Trace elements like selenium and potassium have been studied in relation to cancer development. Serum levels of selenium was increased in oral cancer patients (57) whereas potassium showed strong 
inverse association with oral cancer (43). There is no evidence for direct cause-effect relationship. Selenium has antioxidant activity and is essential for glutathione peroxidase, an enzyme that protects against oxidative tissue damage (38).

Cultural risk factors and dietary factors seems to interplay in the development of oral cancer and precancer (58). Studies have shown the association between smoking and lowering of serum levels of nutrients. For instance, cigarette smokers had lower levels of $\beta$-carotene than non-smokers (59) and also smoking modified the association between dietary and serum $\beta$-carotene (60). The habit of quid chewing also has been shown to reduce serum levels of vitamins A, C, B12, folate and $\beta$-carotene in quid chewers than non-quid-chewers (51). A populationbased case-control study in Malaysia comparing the cultural habits including quid chewing habit, serum micronutrients and oral leukoplakia in two ethnic groups concluded that quid chewing habit masked the protective effect of other serum micronutrients (61). These studies show the inter-association between certain cultural habits and dietary patterns in the development of oral cancer.

\section{Mouthwash:}

The use of mouthwash has been implicated to cause oral cancer (62). Mouthwashes usually contains alcohol as a solvent for other ingredients or as a preservative. Epidemiological evidence demonstrate that the risk of mouthwash causing oral cancer is attributed to the frequency and duration of use and its alcohol content (62). However, there is no cause-effect relationship found between mouthwash and oral cancer. Nevertheless, the dental clinicians must be prudent while advocating mouthwashes/rinses with high alcohol content.

\section{Maté:}

Maté, which is a tea-like beverage consumed in South America and in parts of Europe has been shown to be an independent cause for development of oral and pharyngeal cancers (63). The exact pathogenesis of maté predisposing to oral cancer is still unknown. Many reasons that have proposed for maté's carcinogenicity are thermal injury, solvent for other chemical carcinogens and presence of tannins and N-nitroso compounds (63).

\section{ENVIRONMENTAL FACTORS}

\section{Viral Infections:}

Viruses have been strongly implicated in the development of malignant tumours of the squamous epithelia including the oral squamous epithelium (64). Viral infections of latent or chronic nature are usually responsible for inducing malignant transformation by interfering with the host's cell cycle machinery. For instance, certain viruses can become permanent fixtures and integrate their genome in the host's nucleus, producing factors which cause cellular immortalization. Sometimes, the viruses may produce their own genes by integrating with the host's genes. These viral genes and gene products may affect cell growth and proliferation. Certain viral genes are proto-oncogenes which become oncogenes when inserted into the host's DNA and ultimately resulting in malignant transformation (65). The prototypic viruses implicated in oral cancer development are Human Herpes Virus (mainly Epstein Barr Virus, EBV), Human Papilloma Virus (HPV) and Herpes Simplex Virus $(64,65)$.

EBV causes oral hairy leukoplakia and "lymphoproliferative disease" in immuno-suppressed patients (65). The causal relationship of EBV with oral squamous cell carcinoma is still unclear. Prevalence studies have shown presence of EBV in oral squamous cell carcinoma (OSCC) patients but it does not prove a causal association (66). Cruz et al. (2000) showed that there is no causal role for EBV in oral carcinogenesis. They analysed EBV-DNA positive OSCCs for EBV viral products which are known to be pathogenic in other EBV associated malignancies. They used a variety of techniques including RT-PCR (Reverse Transcription Polymerase Chain Reaction), in situ hybridization and immunohistochemistry and found that none of the pathogenic EBV transcripts were seen in the OSCC samples. They rationalised the presence of EBV DNA detected by PCR in these OSCC patients as reflecting the increased shedding of the virus in the saliva due to associated immunosuppression (67).

HPV are the most common viruses implicated in oral carcinogenesis. HPV are DNA viruses and are epitheliotropic, especially for squamous epithelia. They cause benign proliferative lesions such as papillomas, condyloma acuminatum, verruca vulgaris and focal epithelial hyperplasia (Heck's Disease). Certain HPV types, referred to as 'highrisk' types are associated with oral squamous cell carcinoma and oral premalignant lesions. They are HPVs 16, 18, 31, 33, 35 and 39.

The major evidence of the role of HPV in cancer development is that their genes and gene products are capable of disturbing the cell cycle machinery. HPV encodes two major oncoproteins namely, E6 and E7. The E6 and E7 proteins have been shown to bind and destroy p53 and Rb tumor suppressor genes respectively, thereby disrupting the cell cycle with loss of control on DNA replication, DNA repair and apoptosis $(64,65,68)$.

HPV has been detected in oral squamous cell carcinoma, dysplasia and other benign lesions using various techniques. Some studies have shown HPV presence in normal oral mucosa making the role of HPV in oral carcinogenesis speculative. Recently, a large-scale multinational, case-control study to determine the role of HPV in cancers of oral cavity and oropharynx was carried out by IARC (69). In this 
study, HPV DNA was detected using PCR and it was shown that only $3.9 \%$ of 766 oral cancers were positive for HPV DNA, which is relatively a low prevalence rate compared to previous studies. However, the prevalence of HPV DNA was higher in cancers of oropharynx with $18.3 \%$ of 142 cancers being positive for HPV DNA. HPV DNA was found to be higher in subjects who either had many sexual partners or practiced oral sex. Moreover, HPV 16, which is the most common type found in genital cancers were also the most common in oral cancers, which clearly indicates the possible source of HPV infection in the oral cavity (69).

HPV has been shown only to play a dependent causative role in oral carcinogenesis in an in vitro study by Park and Kang in 2000. The authors attempted to immortalize normal human oral keratinocytes by HPV genome but failed. Later, upon exposure of the same cells to tobacco-related chemical carcinogens, the cells underwent spontaneous mutations and ultimately malignancy. Additionally, this study also showed that the mutation frequency increased with E6 and E7 expression (70). This study revealed that HPV infection alone is not tumourigenic but aids in carcinogenesis when combined with other risk factors like tobacco.

Herpes Simplex Virus (HSV) has not been proven to be the direct cause of oral cancer although several studies show that oral cancer patients have high serum antibody titres to HSV. The available evidences are circumstantial and are rationalized that reactivation of HSV infection is due to immunosuppression, specifically of natural killer lymphocyte activity. Based on the evidence of in vitro studies, the possible role of $\mathrm{HSV}$ in carcinogenesis has been proposed as the enhancement of activation, amplification and overexpression of pre-existing oncogenes such as c-myc and c-erb-B-1 (65).

\section{Fungal Infections:}

Fungal infections caused by Candida species, in particular, Candida albicans has been implicated in the pathogenesis of oral premalignant lesions (71). Superficial fungal hyphae of Candida albicans have been found superimposed on leukoplakia, especially nodular leukoplakia, many of which have undergone malignant transformation. The doubt of whether Candida invasion is a secondary event or causal in oral premalignant lesions is still uncertain and debatable. Candida species are common commensals in the oral cavity which become opportunistic during host's immunosuppression due to systemic diseases or drug therapy. Besides immunocompromised individuals, Candida infection can coexist or be associated with other risk factors like iron-deficiency and in chronic smokers which may prove synergistic in the development of oral cancer. There is evidence that Candida possesses necessary enzymes from dietary substances to produce nitrosamines and chemicals that have been implicated in carcinogenesis (72). A recent study showed relationship between oral yeast carriage and epithelial dysplasia (73). Again, the actual role of yeast in the development of epithelial dysplasia is uncertain.

\section{Immunosuppression:}

Immunosuppressed individuals are more prone to develop oral cancers. HIV infected patients are predisposed to developing Kaposi's sarcoma and lymphomas, although not to oral squamous cell carcinoma. Immunosuppressed organ transplant patients have been shown to develop lip cancers (74) and the possible reason was attributed to increased exposure to solar radiation and other risk factors such as smoking. However, the direct role of immunosuppression with lip cancer development was not proven in this study (74). A recent study showed that there is a rapid progression from oral leukoplakia to OSCC in an immunosuppressed liver transplant recipient (75). The liver transplant patient who was on immunosuppressive treatment regimen developed a homogenous leukoplakia 4 months posttransplant surgery, which transformed to OSCC within next 4 months. This raises the idea that immunosuppression may indeed be a major risk factor for OSCC and warrants more studies on the actual pathogenesis.

\section{Occupational Risks:}

Occupational risks, namely exposure to excessive solar radiation/ ultraviolet light is known to cause lip cancers. UV rays also causes actinic cheilitis which may transform to oral squamous cell carcinomas. Sulfur dioxide, asbestos, pesticide exposures and mists from strong inorganic acids, burning of fossil fuels have been known to cause cancers of posterior mouth, pharynx and larynx (76).

\section{Dental Factors:}

Poor oral hygiene, poor dental status (sharp/ fractured teeth due to caries/trauma), chronic ulceration from an ill-fitting denture has been suggested to promote neoplasm in the presence of other risk factors (10). There has been difficulty in obtaining the evidence whether dental factors influence oral cancer development. This is due to the presence of coexisting risk factors like smoking and alcohol consumption (77). Nevertheless, an experimental study in hamsters (78) has shown that chronic trauma in addition to carcinogen application could promote tumour development. In this study, mechanical irritation by scratching with a pulp cleaner has been shown to significantly increase the incidence of a chemical carcinogen induced tongue carcinoma (78). In addition, Lockhart et al. (77) observed that all 28 intra-oral carcinomas included in their study were seen in areas in contact with teeth 
and/or appliances (77). Although the second finding suggests a relationship between dental factors and oral carcinogenesis, dental status at the time of patient examination is a static observation and only a large prospective trial would resolve this issue (77). Therefore, it is prudent to closely monitor patients with known risk factors for signs and symptoms of irritation from teeth and appliances.

\section{Syphilis:}

Tertiary syphilis had been known to predispose to the development of oral cancer along with other risk factors such as tobacco and alcohol. However, nowadays, tertiary syphilis is rare in clinical practice as the infection is diagnosed and treated before the onset of tertiary stage (10).

\section{GENETIC PREDISPOSITION}

Genetic predisposition has been shown to be an important risk factor in the development of oral squamous cell carcinoma. A study by Copper et al. who followed up first-degree relatives of 105 head and neck cancer patients, found that 31 of these subjects developed cancers of respiratory tract and upper aerodigestive tract (UADT) (79). However, population based studies to determine the genetic or familial disposition to oral cancers are limited by the co-existing risk factors like smoking and alcohol. It is also believed that certain individuals inherit the susceptibility of inability to metabolise carcinogens or pro-carcinogens and/or an impaired ability to repair the DNA damage. As discussed earlier about the metabolism of tobacco carcinogens, genetic polymorphisms in the genes coding for the enzymes (P450 enzymes, xenometabolising enzymes: XMEs) responsible for tobacco carcinogen metabolism are suspected to play key role in the genetic predisposition to tobacco induced head and neck cancers (9).

\section{CONCLUSION}

It is clear from the above review that several risk factors are implicated in the development of oral cancer of which the most common and established are tobacco smoking and betel quid chewing. Nevertheless, many patients are diagnosed with oral cancer despite abstaining from known lifestyle or environmental risk factors where factors like genetic susceptibility are believed to play the causative role. Hence, it is important for the public and the clinicians to be completely aware of the risk factors for oral cancer and it is prudent for dentists to look carefully for early signs of oral cancer while routine examination of the oral cavity especially in patients with history of known risk factors.

\section{REFERENCES}

1. Scully C, Field JK, Tanzawa H Genetic aberrations in oral or head and neck squamous cell carcinoma $(\mathrm{SCCHN})$ : 1. Carcinogen metabolism, DNA repair and cell cycle control. Oral Oncol 2000; 36(3): 256-63.

2. Johnson NW. Aetiology and risk factors for oral cancer. In: Shah JP, Johnson NW, Batsakis JG, eds. (2003) Oral Cancer. London: Martin Dunitz, an imprint of the Taylor \& Francis Group. pp. 33-75.

3. IARC Global cancer rates could increase by $50 \%$ to 15 million by 2020. 2003; IARC Press Release No. 145.

4. Zaridze $\mathrm{G}$, Peto $\mathrm{R}$ Implications and Recommendations. Tobacco: A Major International Health Hazard. IARC Sci Publ 1986; (74): 3-7.

5. IARC IARC Monographs Programme Declares Second-Hand Smoke Carcinogenic To Humans. 2002; IARC Press Release No. 141.

6. Mehta FS, Gupta PC, Daftary DK, Pindborg JJ, Choksi SK An epidemiologic study of oral cancer and precancerous conditions among 101,761 villagers in Maharashtra, India. Int $J$ Cancer 1972; 10(1): 134-41.

7. Hecht SS, Peterson LA, Spratt TE Tobaccospecific nitrosamines. IARC Sci Publ 1994; (125): 91-106.

8. Lawley PD From fluorescence spectra to mutational spectra, a historical overview of DNA-reactive compounds. IARC Sci Publ 1994; (125): 3-22.

9. Johnson N Tobacco use and oral cancer: a global perspective. J Dent Educ 2001; 65(4): 328-39.

10. Johnson NW Orofacial neoplasms: global epidemiology, risk factors and recommendations for research. Int Dent $J$ 1991; 41(6): 365-75.

11. Muir CS, Zaridze DG Smokeless tobacco and cancer: an overview. IARC Sci Publ 1986; (74): $35-44$.

12. WHO. Tobacco or Health: A global overview. In:(1997) Tobacco or Health: A global status report. Geneva: WHO. pp. 5-65.

13. Johnson GK, Squier CA Smokeless tobacco use by youth: a health concern. Pediatr Dent 1993; 15(3): 169-74. 
14. Axell T Occurrence of leukoplakia and some other oral white lesions among 20,333 adult Swedish people. Community Dent Oral Epidemiol 1987; 15(1): 46-51.

15. Larsson A, Axell T, Andersson G Reversibility of snuff dippers' lesion in Swedish moist snuff users: a clinical and histologic follow-up study. J Oral Pathol Med 1991; 20(6): 258-64.

16. Zhang X, Schmitz W, Gelderblom HR, Reichart PA Shammah-induced oral leukoplakia-like lesions. Oral Oncol 2001; 37(7): 609-12.

17. Hashibe M, Mathew B, Kuruvilla B, Thomas G, Sankaranarayanan $\mathrm{R}$, Parkin DM, et al. Chewing tobacco, alcohol, and the risk of erythroplakia. Cancer Epidemiol Biomarkers Prev 2000; 9(7): 639-45.

18. Gupta PC, Mehta FS, Daftary DK, Pindborg JJ, Bhonsle RB, Jalnawalla PN, et al. Incidence rates of oral cancer and natural history of oral precancerous lesions in a 10 -year follow-up study of Indian villagers. Community Dent Oral Epidemiol 1980; 8(6): 283-333.

19. Murti PR, Bhonsle RB, Pindborg JJ, Daftary DK, Gupta PC, Mehta FS Malignant transformation rate in oral submucous fibrosis over a 17-year period. Community Dent Oral Epidemiol 1985; 13(6): 340-1.

20. Jeng JH, Kuo ML, Hahn LJ, Kuo MY Genotoxic and non-genotoxic effects of betel quid ingredients on oral mucosal fibroblasts in vitro. J Dent Res 1994; 73(5): 1043-9.

21. Jeng JH, Chang MC, Hahn LJ Role of areca nut in betel quid-associated chemical carcinogenesis: current awareness and future perspectives. Oral Oncol 2001; 37(6): 477-92.

22. IARC IARC Monographs Programme Finds Betel-Quid and Areca-Nut Chewing Carcinogenic to Humans. 2003; IARC Press Release No. 149.

23. Ko YC, Huang YL, Lee CH, Chen MJ, Lin LM, Tsai CC Betel quid chewing, cigarette smoking and alcohol consumption related to oral cancer in Taiwan. J Oral Pathol Med 1995; 24(10): 450 3.

24. Hindle I, Downer MC, Moles DR, Speight PM Is alcohol responsible for more intra-oral cancer? Oral Oncol 2000; 36(4): 328-33.

25. Blot WJ Alcohol and cancer. Cancer Res 1992; 52(7 Suppl): 2119s-2123s.
26. Blot WJ, McLaughlin JK, Winn DM, Austin DF, Greenberg RS, Preston-Martin S, et al. Smoking and drinking in relation to oral and pharyngeal cancer. Cancer Res 1988; 48(11): 3282-7.

27. Hashibe M, Sankaranarayanan R, Thomas G, Kuruvilla B, Mathew B, Somanathan T, et al. Alcohol drinking, body mass index and the risk of oral leukoplakia in an Indian population. Int $J$ Cancer 2000; 88(1): 129-34.

28. Jaber MA, Porter SR, Gilthorpe MS, Bedi R, Scully C Risk factors for oral epithelial dysplasia - the role of smoking and alcohol. Oral Oncol 1999; 35(2): 151-6.

29. Jaber MA, Porter SR, Scully C, Gilthorpe MS, Bedi R The role of alcohol in non-smokers and tobacco in non-drinkers in the aetiology of oral epithelial dysplasia. Int J Cancer 1998; 77(3): 333-6.

30. Du X, Squier CA, Kremer MJ, Wertz PW Penetration of $\mathrm{N}$-nitrosonornicotine (NNN) across oral mucosa in the presence of ethanol and nicotine. J Oral Pathol Med 2000; 29(2): 80-5.

31. Figuero Ruiz E, Carretero Pelaez MA, Cerero Lapiedra R, Esparza Gomez G, Moreno Lopez LA Effects of the consumption of alcohol in the oral cavity: relationship with oral cancer. Med Oral 2004; 9(1): 14-23.

32. La Vecchia C, Tavani A, Franceschi S, Levi F, Corrao G, Negri E Epidemiology and prevention of oral cancer. Oral Oncol 1997; 33(5): 302-12.

33. Soler M, Bosetti C, Franceschi S, Negri E, Zambon P, Talamini R, et al. Fiber intake and the risk of oral, pharyngeal and esophageal cancer. Int J Cancer 2001; 91(3): 283-7.

34. De Stefani E, Deneo-Pellegrini H, Mendilaharsu M, Ronco A Diet and risk of cancer of the upper aerodigestive tract-I. Foods. Oral Oncol 1999; 35(1): 17-21.

35. De Stefani E, Ronco A, Mendilaharsu M, Deneo-Pellegrini H Diet and risk of cancer of the upper aerodigestive tract-II. Nutrients. Oral Oncol 1999; 35(1): 22-6.

36. Wynder EL, Bross IJ Aetiological factors in mouth cancer; an approach to its prevention. $\mathrm{Br}$ Med J 1957; (5028): 1137-43.

37. IARC Fruits and Vegetables Protective Overall against Cancer. 2003; IARC Press Release No. 144. 
38. Hennekens CH, Stampfer MJ, Willett W Micronutrients and cancer chemoprevention. Cancer Detect Prev 1984; 7(3): 147-58.

39. Garewal H Antioxidants in oral cancer prevention. Am J Clin Nutr 1995; 62(6 Suppl): 1410S-1416S.

40. Garewal HS Carotenoids in oral cancer prevention. Ann N Y Acad Sci 1993; 691: 13947.

41. Tuovinen V, Vaananen M, Kullaa A, Karinpaa A, Markkanen H, Kumpusalo E Oral mucosal changes related to plasma ascorbic acid levels. Proc Finn Dent Soc 1992; 88(3-4): 117-22.

42. Shklar G, Schwartz JL, Trickler DP, Reid S Prevention of experimental cancer and immunostimulation by vitamin $\mathrm{E}$ (immunosurveillance). J Oral Pathol Med 1990; 19(2): 60-4.

43. Negri E, Franceschi S, Bosetti C, Levi F, Conti E, Parpinel M, et al. Selected micronutrients and oral and pharyngeal cancer. Int J Cancer 2000; 86(1): 122-7.

44. Kaugars GE, Silverman S, Jr., Lovas JG, Thompson JS, Brandt RB, Singh VN Use of antioxidant supplements in the treatment of human oral leukoplakia. Oral Surg Oral Med Oral Pathol Oral Radiol Endod 1996; 81(1): 514.

45. Albanes D, Heinonen OP, Taylor PR, Virtamo J, Edwards BK, Rautalahti M, et al. AlphaTocopherol and beta-carotene supplements and lung cancer incidence in the alpha-tocopherol, beta-carotene cancer prevention study: effects of base-line characteristics and study compliance. J Natl Cancer Inst 1996; 88(21): 1560-70.

46. Mitchel RE, McCann RA Skin tumor promotion by Vitamin E in mice: amplification by ionizing radiation and Vitamin C. Cancer Detect Prev 2003; 27(2): 102-8.

47. Schwartz J, Shklar G, Trickler D Vitamin C enhances the development of carcinomas in the hamster buccal pouch experimental model. Oral Surg Oral Med Oral Pathol 1993; 76(6): 71822.

48. Bendich A, Olson JA Biological actions of carotenoids. Faseb J 1989; 3(8): 1927-32.

49. Stich HF, Mathew B, Sankaranarayanan R, Nair MK Remission of precancerous lesions in the oral cavity of tobacco chewers and maintenance of the protective effect of betacarotene or vitamin A. Am J Clin Nutr 1991; 53(1 Suppl): 298S-304S.

50. Stich HF, Rosin MP, Hornby AP, Mathew B, Sankaranarayanan R, Nair MK Remission of oral leukoplakias and micronuclei in tobacco/ betel quid chewers treated with beta-carotene and with beta-carotene plus vitamin A. Int J Cancer 1988; 42(2): 195-9.

51. Ramaswamy G, Rao VR, Kumaraswamy SV, Anantha N Serum vitamins' status in oral leucoplakias - a preliminary study. Eur J Cancer B Oral Oncol 1996; 32B(2): 120-2.

52. Sankaranarayanan R, Mathew B, Varghese C, Sudhakaran PR, Menon V, Jayadeep A, et al. Chemoprevention of oral leukoplakia with vitamin A and beta carotene: an assessment. Oral Oncol 1997; 33(4): 231-6.

53. Garewal HS, Katz RV, Meyskens F, Pitcock J, Morse D, Friedman S, et al. Beta-carotene produces sustained remissions in patients with oral leukoplakia: results of a multicenter prospective trial. Arch Otolaryngol Head Neck Surg 1999; 125(12): 1305-10.

54. Royack GA, Nguyen MP, Tong DC, Poot M, Oda D Response of human oral epithelial cells to oxidative damage and the effect of vitamin E. Oral Oncol 2000; 36(1): 37-41.

55. Benner SE, Winn RJ, Lippman SM, Poland J, Hansen KS, Luna MA, et al. Regression of oral leukoplakia with alpha-tocopherol: a community clinical oncology program chemoprevention study. J Natl Cancer Inst 1993; 85(1): 44-7.

56. Takezaki T, Hirose K, Inoue M, Hamajima N, Kuroishi T, Nakamura S, et al. Tobacco, alcohol and dietary factors associated with the risk of oral cancer among Japanese. Jpn J Cancer Res 1996; 87(6): 555-62.

57. Zheng W, Blot WJ, Diamond EL, Norkus EP, Spate V, Morris JS, et al. Serum micronutrients and the subsequent risk of oral and pharyngeal cancer. Cancer Res 1993; 53(4): 795-8.

58. Zain RB Cultural and dietary risk factors of oral cancer and precancer-a brief overview. Oral Oncol 2001; 37(3): 205-10.

59. Stryker WS, Kaplan LA, Stein EA, Stampfer MJ, Sober A, Willett WC The relation of diet, cigarette smoking, and alcohol consumption to plasma beta-carotene and alpha-tocopherol levels. Am J Epidemiol 1988; 127(2): 283-96. 
60. Jarvinen R, Knekt P, Seppanen R, Heinonen M, Aaran RK Dietary determinants of serum betacarotene and serum retinol. Eur J Clin Nutr 1993; 47(1): 31-41.

61. Zain RB, Fukano F, Razak IA, Shanmuhasuntharam P, Ikeda N, Rahman ZAA. Risk factors for oral leukoplakia: a comparison of two ethnic groups in Malaysia. In:(1999) Oral Oncol: Macmillan India. pp. 207-210.

62. Winn DM, Blot WJ, McLaughlin JK, Austin DF, Greenberg RS, Preston-Martin S, et al. Mouthwash use and oral conditions in the risk of oral and pharyngeal cancer. Cancer Res 1991; 51(11): 3044-7.

63. Goldenberg D Mate: a risk factor for oral and oropharyngeal cancer. Oral Oncol 2002; 38(7): 646-9.

64. Scully C Oncogenes, tumor suppressors and viruses in oral squamous carcinoma. J Oral Pathol Med 1993; 22(8): 337-47.

65. Flaitz CM, Hicks MJ Molecular piracy: the viral link to carcinogenesis. Oral Oncol 1998; 34(6): 448-53.

66. Sand LP, Jalouli J, Larsson PA, Hirsch JM Prevalence of Epstein-Barr virus in oral squamous cell carcinoma, oral lichen planus, and normal oral mucosa. Oral Surg Oral Med Oral Pathol Oral Radiol Endod 2002; 93(5): 586-92.

67. Cruz I, Van Den Brule AJ, Brink AA, Snijders PJ, Walboomers JM, Van Der Waal I, et al. No direct role for Epstein-Barr virus in oral carcinogenesis: a study at the DNA, RNA and protein levels. Int $J$ Cancer 2000; 86(3): 356-61.

68. Ke LD, Adler-Storthz K, Mitchell MF, Clayman GL, Chen $\mathrm{Z}$ Expression of human papillomavirus E7 mRNA in human oral and cervical neoplasia and cell lines. Oral Oncol 1999; 35(4): 415-20.

69. Herrero R, Castellsague X, Pawlita M, Lissowska J, Kee F, Balaram P, et al. Human papillomavirus and oral cancer: the International Agency for Research on Cancer multicenter study. J Natl Cancer Inst 2003; 95(23): 1772-83.
70. Park NH, Kang MK Genetic instability and oral cancer. Electronic Journal of Biochemistry 2000; 3(1): 66-71.

71. Rindum JL, Stenderup A, Holmstrup P Identification of Candida albicans types related to healthy and pathological oral mucosa. J Oral Pathol Med 1994; 23(9): 406-12.

72. Krogh P, Hald B, Holmstrup P Possible mycological etiology of oral mucosal cancer: catalytic potential of infecting Candida albicans and other yeasts in production of $\mathrm{N}$ nitrosobenzylmethylamine. Carcinogenesis 1987; 8(10): 1543-8.

73. McCullough M, Jaber M, Barrett AW, Bain L, Speight PM, Porter SR Oral yeast carriage correlates with presence of oral epithelial dysplasia. Oral Oncol 2002; 38(4): 391-3.

74. Harris JP, Penn I Immunosuppression and the development of malignancies of the upper airway and related structures. Laryngoscope 1981; 91(4): 520-8.

75. Hernandez G, Arriba L, Jimenez C, Bagan JV, Rivera B, Lucas M, et al. Rapid progression from oral leukoplakia to carcinoma in an immunosuppressed liver transplant recipient. Oral Oncol 2003; 39(1): 87-90.

76. Thornhill MH The sun, the ozone layer and the skin: the role of ultraviolet light in lip and skin cancer. Dent Update 1993; 20(6): 236-40.

77. Lockhart PB, Norris CM, Jr., Pulliam C Dental factors in the genesis of squamous cell carcinoma of the oral cavity. Oral Oncol 1998; 34(2): 1339.

78. Fujita K, Kaku T, Sasaki M, Onoe T Experimental production of lingual carcinomas in hamsters by local application of 9, 10dimethyl-1, 2-benzanthracene. J Dent Res 1973; 52(2): 327-32.

79. Copper MP, Jovanovic A, Nauta JJ, Braakhuis BJ, de Vries N, van der Waal I, et al. Role of genetic factors in the etiology of squamous cell carcinoma of the head and neck. Arch Otolaryngol Head Neck Surg 1995; 121(2): 15760 . 